\title{
De la crisis migratoria a la crisis sistémica: desplazamiento forzado en la crisis terminal del capitalismo
}

From the migration crisis to the systemic crisis: forced displacement in the terminal crisis of capitalism

José A. Zamora Instituto de Filosofía del CSIC joseantonio.zamora@cchs.csic.es

Orcid: 0000-0002-1722-476X DOI: http://dx.doi.org/10.15366/bp.2020.23.002 Bajo Palabra. II Época. No23. Pgs: 49-72 


\section{Resumen}

La crisis migratoria y de refugio que vive Europa desde 2015 solo puede ser entendida dentro de la crisis del régimen migratorio neoliberal. Al mismo tiempo, en esta crisis convergen los elementos más significativos de la crisis sistémica que sufren las sociedades capitalistas desde los años 1970 y que se ha agudizado con el crash financiero del 2008. La reacción de los países ricos a los desplazamientos forzados es un signo más de que la respuesta mayoritaria a la crisis sistémica conduce a un callejón sin salida.

Palabras clave: migración, capitalismo, refugio, crisis.

\section{Abstract}

The migration and refugee crisis that Europe has been experiencing since 2015 can only be understood within the crisis of the neoliberal migration regime. At the same time, this crisis brings together the most important elements of the systemic crisis that capitalist societies have been suffering since the 1970s and which was exacerbated by the financial crash of 2008. The reaction of the rich countries to the forced displacements is another sign that the majority reaction to the system crisis is leading to a dead end.

Keywords: migration, capitalism, refuge, crisis. 
L

as crisis humanitarias provocadas por los desplazamientos masivos de personas que intentan escapar de situaciones de violencia y destrucción extremas no son excepciones en el último siglo. El encadenamiento de sucesivas crisis de este tipo en las fronteras de Europa tampoco se ha interrumpido en las últimas décadas, aunque las causas desencadenantes hayan ido variando, desde la guerra de los Balcanes a la guerra en Siria, pasando por la guerra de Afganistán, la guerra de Irak, los diferentes conflictos en el África subsahariana y las llamadas "primaveras árabes". Tampoco los efectos letales del blindaje de las fronteras, por desgracia, son una novedad. La organización United for Intercultural Action habla de 30.000 muertos en el Mediterráneo entre 1993 y 2014. Si nos atenemos a las últimas estadísticas, ya habremos alcanzado casi los 40.000. Bien entendido que esa cifra se refiere exclusivamente a las muertes que han podido ser registradas. La visita del Papa Francisco a la isla de Lampedusa en julio de 2013 tras el naufragio que costó la vida a más de 300 desplazados en barco o la fotografía de Aylan Kurdi, un niño sirio de tres años muerto en una playa de Turquía cuando trataba de emigrar a Europa con su familia, han sido momentos de escandalización de las opiniones públicas que no producen efectos políticos importantes o duraderos, ni en las políticas de inmigración ni en las de asilo. El 19 de abril de 2015 se volvió a producir otro naufragio frente a las costas de Lampedusa en el que murieron esta vez 800 personas, sin provocar ya ningún escándalo mediático significativo. Y todavía hoy continúa la tragedia, cuando las poblaciones europeas miran exclusivamente a los efectos internos de la pandemia del Covid-19. La sucesión de naufragios y las cifras de muertes se mantienen. La situación insostenible en los múltiples campos de refugiados distribuidos por casi todos los países fronterizos de la franja sur de Europa se agrava hasta cotas inimaginables. A veces alguna de las numerosas catástrofes se cuela en los telediarios o se hace eco de ella la prensa. Después se dan las noticias sobre el tiempo y se emite el concurso o la serie de moda. Nada se interrumpe, todo sigue su curso. Como certeramente dijera Walter Benjamin, la catástrofe no es lo que está por venir; que todo siga su curso normal: eso es la catástrofe.

Lo que la opinión pública europea denominó "crisis de los refugiados" se produjo como consecuencia de la operación Tritón, que sustituía a la operación Mare Nostrum liderada y protagonizada por el gobierno italiano tras la catástrofe de Lampedusa, una operación que, por cierto, salvó a más de 100.000 personas en situación de naufragio. Los Estados de la Unión Europea (UE) consideraban que esta 
operación era demasiado costosa, producía un "efecto llamada" y debía ser sustituida por un control más riguroso de las fronteras a cargo del FRONTEX (Agencia Europea para la Gestión de la Cooperación Operativa en las Fronteras Exteriores de los Estados miembros de la Unión). El modelo declarado de la operación Triton era la misión militar desarrollada frente a las costas de Somalia a comienzo de 1990 para combatir la piratería contra las flotas pesqueras europeas (que operaban ilegalmente), la llamada operación Atalanta. En primer plano se ponía, pues, el carácter militar de la operación. El efecto fue un desplazamiento de las rutas llamadas irregulares hacia Grecia, a cuyas costas llegaron en la primera mitad de 2015 más de 100.000 refugiados.

Lo que desencadenó la llamada crisis es la apertura de la frontera de Turquía con la UE para el paso de refugiados que se encontraban en su territorio y la negativa del gobierno de Syriza en Grecia a seguir con las operaciones ilegales de Pushback (Chick 2015) y a dar cumplimiento al Reglamento de Dublín, que prevé la obligación del país de la UE que recibe en primer lugar a los inmigrantes o solicitantes de asilo a asumir el procedimiento sobre acogida o rechazo. Esto provocó que miles de regufiados alcanzaran países como Austria o Alemania por la llamada "ruta de los Balcanes".

A partir de ese momento se desencadenó un tenso debate y un conjunto de negaciaciones, con acuerdos que no se cumplían, en torno al reparto de cuotas entre los países de la UE, y se produjo un nuevo cierre de fronteras y un escandaloso acuerdo de la UE con Turquía para que cortase el flujo de refugiados hacia Grecia. Según la propia comisión Europea el tránsito por dicha frontera se redujo de 7000 personas al día en 2015 a 47 en mayo de 2016. No cabe duda que para los promotores del acuerdo con Turquía este había sido todo éxito, aunque supusiese una suspensión de facto de la Convención de Ginebra sobre el Estatuto de los Refugiados. Resulta verdaderamente llamativo que en este acuerdo vergonzoso los mismos gobiernos que venían apelando a la distinción entre "migración económica" y "asilo" para rechazar la entrada de los llamados inmigrantes "irregulares", tildados de "falsos demandantes de asilo", ahora aplicaran el termino "migrantes" para referirse a los demandantes de asilo que huyen de situaciones de conflicto bélico y de persecución política, con el único fin de poder rechazarlos. Algo verdaderamente ingnominioso que ha culminado en la persecución y la obstaculización de la labor humanitaria de rescate de náufragros o la financiación de las pratrullas criminales de pretendidos "guardacostas" libios, lo que ha supuesto que los fondos europeos han acabado en manos de traficantes de seres humanos en Libia con conocimiento de la ONU. Los que proclaman combatir el tráfico ilegal de personas han actuado como sus verdaderos promotores. El progresivo vaciamiento del marco político-jurídico de 
los Estados de Derecho en Europa se hace especialmente evidente en relación con los flujos migratorios y de refugiados desde hace décadas (FitzGerald 2019: 40; Silveira Gorski 2008). Sin embargo, esto no ha impedido, según ACNUR, que unas 63.311 personas arriesgaran sus vidas en el Mediterráneo intentando llega a Europa en 2019 y que entre ellas más de mil hayan podido perder la vida ahogadas. Algo que solo se comprende si se atiende a las situaciones de las que huyen.

\section{Régimen fronterizo: movilidad, control y violencia}

Este ESTADO DE COSAS EXIGE REPENSAR el significado del concepto de frontera y el papel que ha jugado en la constitución y reproducción de las formaciones sociales capitalistas. Quizás resulte una obviedad, pero puede que no esté de más recordar las palabras de Georg Simmel (1908: 697): "las fronteras no son fenómenos espaciales que tienen un impacto social, sino hechos sociales que toman una forma espacial". Étienne Balibar llamaba la atención en 1998 sobre el hecho de que las fronteras "ya no están en los lindes, sino que son un sitio institucional que puede materializarse sobre el terreno e inscribirse en el mapa" (Balibar 1998: 217). Considerar, por tanto, las fronteras como meras líneas de demarcación territorial que separan dos áreas en las se aplica una jurisdicción específica (estatal o interestatal) no resulta suficiente y mucho menos en relación con los flujos migratorios ${ }^{1}$ : "la imagen ampliamente difundida por los estudios críticos recientes de la frontera como un muro, o como un dispositivo que sirve ante todo y principalmente para excluir, termina resultando engañosa" (Mezzadra y Neilson 2017: 25). Aun a riesgo de una pérdida de precisión y diferenciación, creo que, para abordar las nuevas situaciones, quizás sea preciso considerar la "frontera" como un dispositivo múltiple de regulación de los flujos y la movilidad tanto de personas, como de información, mercancías, capitales, servicios, etc. que actúa tanto dentro de los Estados, como entre ellos (Balibar 2003: 19). Es un dispositivo con múltiples dimensiones (jurí-

\footnotetext{
${ }^{1}$ Esto se hace evidente, por ejemplo, cuando se tiene en cuenta el así llamado "cordón sanitario" construido fuera de las fronteras de Unión Europea por medio de acuerdos o tratados con terceros países, que ayuda a externalizar y trasladar los controles fronterizos más allá de los límites territoriales (Bukel 2015). En otro sentido, también se pueden considerar los procesos de producción de inmensos slums en ciertas áreas de aquellos países a los que se desplazan las cadenas de producción con bajo valor añadido. Las migraciones internas, dentro de las fronteras estatales, van asociadas a violentas distribuciones espaciales de asimetrías indispensables para movilizar la fuerza de trabajo en condiciones específicas, algo que se consigue sin la mediación de las fronteras estatales. Finalmente, otro fenómeno que permite ir más allá del concepto de frontera territorial es el de los dispositivos de "amenaza prolongada” de expulsión por medio de controles y centros de internamiento (De Genova y Peutz 2010). Fronteras que podríamos llamar "interiores" pero que actúan sobre todo amedrentando a inmigrantes sin papeles, con el mismo efecto de producir unas condiciones específicas de fijación de la fuerza de trabajo.
} 
dicas, infraestructurales, técnicas, policiales, informacionales, etc.) que sirve para facilitar, dificultar, impedir o distribuir los flujos, para lo cual adquiere cristalizaciones diferentes con densidad variable. La cuestión crucial entonces es entender qué función posee ese dispositivo y cómo se transforma.

En primer lugar, más que una función de inclusión/exclusión pura, este dispositivo posee una función de regulación y gobierno de los modos de inclusión en una forma específica de relaciones sociales, la capitalista, que siguiendo a Mezzadra y Neilson podríamos definir como "inclusión diferencial" (2017: 44; 2014), por más que esa forma de inclusión suponga para ciertos individuos la exclusión radical por medio de la muerte en la frontera. Por lo general, se suele ver como un mecanismo que impide o dificulta el acceso a una comunidad política y a su territorio, así como a los bienes sociales, económicos y políticos que produce esa comunidad (fundamentalmente los derivados del estatus de ciudadanía), pero esta perspectiva es claramente insuficiente, porque siempre se trata de un doble juego de movilización e inmovilización, así como de una compleja estratificación del disfrute de esos bienes. Un disfrute, por cierto, que puede configurarse de modo diferente en cada momento independientemente de estatuto jurídico-político de los "beneficiarios". Ninguno de esos dos momentos - movilización e inmovilización- está libre de coacción (y de resistencias).

Para los economistas clásicos las relaciones sociales bajo la forma "capital" aparecen como unas relaciones jurídicas entre libres e iguales que establecen pactos y contratos en un espacio común que es el mercado. Las diferencias de poder en la negociación de esos pactos, si respetan el marco jurídico, son resultado del mérito, la pericia, la laboriosidad o la asunción de riesgos desplegadas bien con carácter previo, en el estado de naturaleza, bien dentro de la sociedad civilizada. Lo que Marx describió con el concepto de "acumulación primitiva" en la fase de constitución del sistema capitalista recuerda, sin embargo, la violencia inscrita en el proceso de producción de la fuerza de trabajo "libre" y cómo la "libertad formal" es inseparable de las condiciones que obligan a los portadores de la fuerza de trabajo a someterse a las obligaciones contractuales que impone su mercantilización: "sistemas que embridan el libre movimiento del trabajo y que constituyen el 'lado oscuro' del proceso por medio del cual se fue constituyendo la 'economía del trabajo asalariado' en el centro del sistema capitalista” (Mezzadra 2005: 89). Y que, añadiría, se trata de un proceso que se vuelve a repetir en diferentes momentos y en nuevas zonas bajo premisas sociales e históricas cambiantes. Lo importante es que se trata de procesos que están al servicio de la imposición de la forma básica de integración social a través del trabajo asalariado, lo que no excluye, como veremos, sino que exige formas escindidas de apropiación de la información, la naturaleza, 
la fuerza de trabajo, etc. subalternas y complementarias a la explotación bajo la relación salarial o mercantil.

Veamos algunos ejemplos de aquello a lo que me refiero en relación con los flujos migratorios. Las cifras de las migraciones interiores en China hacen palidecer las de las migraciones "laborales" hacia los países industrializados, pero quedarían fuera de nuestra atención si nos fijamos solo en las fronteras estatales. ${ }^{2}$ Esas migraciones "internas" tienen relación directa con el traslado de eslabones de la cadena productiva con bajo valor añadido a los países de las así llamadas economías "emergentes". Por no hablar de la proliferación de lo que se conoce con el término de "maquilas", esto es, la creación de enclaves interiores, pero con un grado de "exterritorialidad" regulada jurídicamente que permite una explotación de la fuerza de trabajo bajo condiciones especiales (Ribas Mateos 2011). La conexión y las analogías de estos enclaves con las migraciones laborales hacia los países ricos también se perderían de vista, si quedamos atrapados por la visión de las fronteras territoriales estatales. Del mismo modo, las migraciones laborales entre los años 1950 y 1970 desde el sur de Europa hacia los países demandantes de fuerza de trabajo en el centro y norte de Europa tuvieron unas características específicas muy distintas de las que se producen a partir de los ańos 1980, algo que no se explica fundamentalmente por los cambios en los controles fronterizos y en la libertad de movimientos en la Unión Europea a partir de los Acuerdos de Schengen. Como veremos, el cambio de régimen migratorio estuvo asociado a la transformación de los mercados de trabajo, que, a su vez, explica en buena medida las nuevas estrategias de irregularización de la inmigración de terceros países en toda Europa (Jansen, Celikates y Bloois 2015; González Cámara 2011: 120 y sigs.). En todos estos casos se trata de procesos de movilización y fijación de la fuerza de trabajo bajo unas determinadas condiciones de explotación que se sirven de modificaciones en el dispositivo frontera entendido en un sentido amplio.

En segundo lugar, este dispositivo tiene la función de producir y reproducir asimetrías (económicas, jurídicas, comerciales, de acceso a recursos, simbólicas, etc.). La heterogeneidad espacial y temporal es un factor determinante de la producción de valor y del sometimiento de la fuerza de trabajo a la forma mercancía. Como señala Balibar (2003: 44) siguiendo el planteamiento de la "economía-mundo" aportado por Wallerstein (1984), el mito liberal de un mercado universal abierto no responde en absoluto a la realidad. Dicho mercado no es y no ha sido nunca un conjunto homogéneo y simétrico. La concentración de poder económico que

\footnotetext{
${ }^{2}$ El National Bureau of Statistics de China estima que cerca de 269 millones de trabajadores migrantes internos se están desplazando de las áreas rurales a las ciudades en crecimiento (Huiyao 2015).
} 
acompaña el proceso de acumulación capitalista exige la división en una pluralidad de "unidades políticas" que permitan el empleo de medios extra-económicos que aseguren formas de apropiación o de monopolio. Estos medios son imprescindibles para que funcione la lógica de acumulación y no podrían constituirse y reproducirse sin instrumentos de coacción política o jurídica (Gerstenberger 2017). En el sistema-mundo capitalista, el conjunto de instrumentos de coacción y de gobierno del conflicto social adoptan la forma de Estado nacional. Ni la forma Estado ni la forma nación son desarrollos contingentes en relación con dicho sistema-mundo. Y mucho menos son formas contradictorias con sus exigencias objetivas. Así pues, globalización y formación de Estados nacionales son dos caras de la misma moneda y en absoluto realidades contrapuestas o contradictorias, como a veces se quiere hacer ver. La sorpresa ante el hecho de que los flujos financieros sean regulados de manera diferente a los de personas no es sino una muestra de ingenuidad. Lo que puede parecer una incoherencia es todo lo contrario, ambos desarrollos corresponden a la misma lógica con la que se conforman las relaciones sociales en el sistema-mundo capitalista. Desde esta perspectiva habría que hablar de una "necesidad" de las fronteras, por más que desde el punto de vista del destino individual estar a un lado o al otro de una determinada frontera aparezca como algo azaroso que escapa a la responsabilidad de los individuos (Velasco 2016).

Pero el dispositivo "frontera" posee otra significación añadida en relación con la constitución y reproducción de la forma de explotación de la fuerza de trabajo para la producción de valor capitalizable. Esa otra significación es la que intenta mostrar el concepto de "frontera mercantil". Como hemos visto, el régimen westfaliano de división de Europa en Estados nacionales suponía ya una organización del espacio global y proporcionaba un modelo para el reparto colonial del mundo. En ese régimen quedan diseñadas no solo las relaciones entre los Estados nacionales europeos, sino también las relaciones entre Europa y sus exteriores. La geografía global es organizada por el capital y el Estado según un modelo de expansión e incorporación a la revalorización del capital de la naturaleza humana y extrahumana exterior a las fronteras europeas. La competencia y la lucha entre Estados por la hegemonía mundial es el medio de expansión del propio sistema capitalista global y de hegemonización mundial de la forma "capital". Una reconstrucción de este complejo y variado proceso desborda el propósito de esta contribución, pero a nadie se lo oculta que la cartografía global del capitalismo ha desplegado una violencia devastadora y producido sufrimientos ingentes hasta hoy.

Con todo, creo que es interesante recoger aquí las reflexiones de Jason W. Moore (2003, 2013a, 2012b; 2014) en torno a las "fronteras mercantiles". El proceso de constitución de lo que Moore llama la "ecología-mundo" capitalista supone una 
configuración de la naturaleza humana y extra-humana por la forma mercancía de valorización del capital. Dicha configuración está presidida por un agotamiento acelerado de la tierra y la fuerza de trabajo en el curso normal de apropiación y explotación, también como fuente de valor abstracto. La "frontera mercantil" remite al carácter constitutivo de un "afuera" de la relación de valorización que, sin embargo, permite a la lógica de revalorización y acumulación reconstituirse y mantenerse en el tiempo. Así pues, "el capitalismo no sólo tiene fronteras, sino que se define fundamentalmente por el movimiento de fronterización" (Moore 2014: 302). Es la apropiación de frontera lo que produce e incorpora a la expansión del valor-capital la naturaleza humana y extra-humana baratas (energía, alimentos, materias primas) que permiten nuevas ondas de acumulación, es decir, un aumento del volumen de material por encima del aumento de trabajo abstracto implicado en su producción. Las fronteras juegan un papel decisivo en la producción (violenta) de esa naturaleza humana y extra-humana baratas que antes de su apropiación están fuera del circuito del capital, pero contribuyen de modo decisivo a saldar la cuenta de su acumulación interminable. Digamos que la acumulación por capitalización no habría podido producirse sin una acumulación por apropiación. "El saqueo de las zonas de frontera y los avances en la productividad del trabajo de la metrópolis forman un todo orgánico" (Moore 2013a: 14).

Ese movimiento de frontera integra el desarrollo de los Estados nacionales y los imperios coloniales, la organización de los mercados transcontinentales de materias primas y manufacturas, el comercio de esclavos y las formas de semi-esclavitud en la explotación de la fuerza de trabajo en las colonias (Damir-Geilsdorf et al. 2016). Hablar del capitalismo como movimiento de fronterización no significa negar la revalorización del capital y la mercantilización del trabajo como eje fundamental de la dinámica del capitalismo, pero sí entender por qué dicha dinámica ha necesitado a lo largo de su historia de una expansión de la extracción por apropiación hacia regiones de poca o mínima mercantilización. Entender esto permite asimismo comprender las diferentes formas de producción de fronteras como modelo histórico-geográfico de apropiación secuencial de fuerza de trabajo barata, en cuyo horizonte se inscribirían tanto los movimientos de deslocalización de la producción, como los movimientos migratorios. Pero, sobre todo, ayuda a comprender la necesidad y la permanente transformación del dispositivo "frontera". Un capitalismo sin fronteras es un oxímoron. Y una contradicción pedir la eliminación de las fronteras y asumir al mismo tiempo como inevitable la pervivencia del sistema capitalista. Con todo, en la actualidad asistimos a una casi completa incorporación de la naturaleza humana y extra-humana al movimiento de valorización y esto supone quizás que nos dirigimos hacia una crisis de acumulación que ya no podrá recurrir 
a las "fronteras mercantiles" para su superación. Este horizonte podría ser el determinante de la crisis del régimen migratorio neoliberal y su transformación desde una integración a través de la precarización de la fuerza de trabajo hacia un bloqueo cada vez más riguroso del acceso, como han puesto de relieve las medidas de EEUU y de la UE en la crisis de refugiados. Con todo, en esta crisis del régimen migratorio neoliberal están implicadas otras dinámicas estructurales que conviene analizar.

\section{Régimen migratorio: economía de la irregularidad institucionalizada}

Sin Negar la pertinencia de otros enfoques en el abordaje y en el análisis del régimen migratorio neoliberal y su crisis, creemos que es fundamental atender a las dinámicas estructurales de carácter político y económico que determinan el marco en el que se producen los conflictos y las prácticas o los discursos de los actores sociales que los alimentan. El nexo entre economía capitalista y política migratoria no explica todo ni debe servir para ignorar o minimizar la importancia de las prácticas y discursos de quienes tratan de imponer o de modificar, resistir e incluso abolir el régimen migratorio neoliberal, tampoco las configuraciones cambiantes y la diversidad de dimensiones implicadas en dicho régimen (Transit 2007). No cabe duda que resaltar este aspecto ha sido una aportación fundamental de la perspectiva "autonomista" (Mezzadra 2013). Sin embargo, que las dinámicas estructurales sean cristalizaciones de prácticas y discursos sociales no impide que su resultado produzca estructuras y dinámicas en el sentido que Marx daba al concepto forma. Sin atender a las contradicciones estructurales de la constitución capitalista de las formaciones sociales se puede producir una peligrosa sobrevaloración de las prácticas y los discursos que construyen dinámicamente el régimen migratorio (Hess y Kasparek 2010). Las contradicciones y las dinámicas estructurales generales no se explican a partir de dicho régimen, sino al contrario. La profunda crisis a la que se enfrenta hoy el sistema capitalista no es resultado ni puede explicarse desde el régimen migratorio y su crisis. Más bien establece unas condiciones que sobredeterminan dicho régimen. La fase de profundos cambios de las políticas sociales y económicas que siguió a la crisis del fordismo supuso la creación en Europa de un mercado único en abierta competencia dentro del mercado global mundial, algo que exigía el control del acceso al mercado de trabajo europeo bajo unas determinadas condiciones. Y estas condiciones afectaban de modo especial a las políticas migratorias. Esto es lo que ha llevado a hablar de "migración neoliberal" (Karakayali 2015).

El punto de partida de un análisis crítico del régimen migratorio neoliberal pasa por atender a la inestabilidad y la crisis del proceso de acumulación capitalista que 
se remonta a los ańos 1970 y se manifiesta ahora como una multicrisis (Demirovic 2011; Kliman 2012). El giro neoliberal de las políticas económicas, que pretendía dar respuesta a la crisis del fordismo, consiguió reconfigurar las estructuras y dinámicas económicas, sociales y políticas en el conjunto de planeta. Las contradicciones que se derivan de esa reconfiguración implican problemas, conflictos y crisis relacionados con los movimientos migratorios y su control, que hasta ahora han representado más bien una agudización de las contradicciones. Dicha agudización ha encontrado expresión política en algo que podría calificarse de progresivo vaciamiento de los Estados de derecho. Las contradicciones y su expresión política se concretizan de manera diferente en las periferias y en los centros de la economía capitalista y dentro de ambos en constelaciones regionales y estatonacionales diversas. Sin embargo, sin negar esas particularidades, creo que las contradicciones fundamentales poseen un carácter estructural global (Mateo 2015).

En los países centrales de la economía capitalista las transformaciones del modelo empresarial y el progresivo debilitamiento de los logros del Estado social han conducido a una gran transformación del sistema laboral y de la estructura de clases de la sociedad industrial. Una de las consecuencias más significativas ha sido la generación de una economía dividida, en la que el sector de las relaciones laborales normalizadas es sometido de modo creciente a la presión de un sector sin demasiada protección y vulnerabilizado. Pero no todo ha quedado en generar una "subclase" de constitución reciente conocida como "working poor" o "precariado", sino que también se han producido pérdidas de ingresos y empeoramiento en el régimen de trabajo y en el estatus social de amplias capas, que poco a poco van incluyendo a más asalariados (Domínguez \& Moreno 1997).

Los efectos sobre las periferias de las estrategias de acumulación neoliberal han generado para grandes capas de población unas condiciones de vida marcadas por la falta de perspectiva o unas formas de inclusión en estructuras de producción globalizada que podríamos llamar draconianas. Las formas locales de agricultura de subsistencia se han visto desplazadas en gran parte por los productos agrícolas subvencionados de los países ricos. Las denominadas zonas de libre comercio han impuesto el dominio de los grandes consorcios transnacionales sobre las industrias locales. El acaparamiento neoimperialista de recursos y tierras se ha producido bajo unas condiciones de abuso y explotación y con unos efectos demoledores sobre las poblaciones autóctonas. A esto se une el desigual impacto de los procesos de destrucción medioambiental y la incapacidad del sistema productivo capitalista para incorporar a una relación laboral rentable a millones de seres humanos, después de haber destruido formas de subsistencia no capitalista. Todos estos procesos han contribuido decisivamente al debilitamiento y la degradación de las estructuras es- 
tatales o generado conflictos bélicos que son la primera causa de los desplazamientos masivos. Naturalmente, las dinámicas vinculadas a la acumulación capitalista no son el único factor implicado, pero juegan un papel determinante (Bedszent 2014). Es más, la última forma de sostener dicho proceso de acumulación por medio de la intensificación de la expropiación a escala global (Harvey 2003) no ha hecho más que intensificar los desplazamientos forzados o potenciados de millones de personas.

Esto obliga a pensar y juzgar la violencia de las fronteras en relación con la intensificación de la trasnacionalización de la producción, la comercialización y la financiación en el capitalismo globalizado. La casi eliminación de fronteras para las mercancías, el capital, los servicios, la clase directiva, etc. se acompaña de una creciente impenetrabilidad de las fronteras de todo tipo, erigidas contra los empobrecidos del planeta en las metrópolis del bienestar. Las fronteras de los Estados nacionales han sido al mismo tiempo debilitadas y reforzadas o, quizás habría que decir, refuncionalizadas al servicio de un reordenamiento global de la relación de inclusión y exclusión de los grupos poblacionales compatibles e incompatibles con la capitalización del planeta. Los sistemas de control fronterizo y la violencia que despliegan están al servicio de la reproducción de una división global del trabajo y del desigual reparto de la riqueza, las oportunidades de vida y la paz o la violencia.

Esto afecta de manera muy importante a la configuración de los mercados de trabajo. No en todas las sociedades capitalistas poseen las mismas características, pero el triunfo de las políticas económicas neoliberales ha acelerado en los países más ricos la tendencia a la segmentación de la fuerza de trabajo con múltiples manifestaciones. Hemos asistido a una creciente externalización empresarial de las actividades por medio de la proliferación de sistemas de subcontratación bajo control centralizado y con acaparamiento de los beneficios por los grandes grupos empresariales. A esto se ha unido el crecimiento de la flexibilización y la temporalidad, la pérdida de capacidad negociadora de los trabajadores, la dualización y polarización del escalafón profesional, con un nivel directivo y de gestión perceptor de ingresos de lujo y unos niveles inferiores que ven disminuir desde hace décadas su participación en la apropiación de la plusvalía generada por el trabajo. Y, finalmente, el desempleo y la subproletarización de una parte de la mano de obra con una relación sólo esporádica con el mercado de trabajo ha conducido a la precarización de una parte importante del empleo (Díaz-Salazar 2003; Alonso 1999).

Es más, en ciertos sectores productivos estos procesos han estado unidos en los últimos ańos a un crecimiento de la economía sumergida. En la agricultura, la hostelería-restauración y los servicios menos cualificados (limpieza, servicio doméstico, etc.) la incidencia de la economía sumergida es muy elevada. Es sobradamente 
conocido que la irregularidad conlleva desprotección jurídica, social y sindical de los trabajadores. Dada esta situación del mercado de trabajo, la inserción laboral de la mayoría de los inmigrantes se viene produciendo en los sectores económicos con más incidencia de la economía sumergida y en los segmentos de empleo más precarios y descualificados, con mayor grado de irregularidad y más desprotegidos. Si existe una tendencia general a la precarización del empleo puede decirse que los inmigrantes representan la avanzadilla de dicha precarización. Y lo mismo ocurre con el desempleo, que los inmigrantes sufren con mayor intensidad (Rodríguez Rodríguez 2013: 75ss).

Existe una clara disonancia entre el discurso "oficial" sobre un enfoque global de la inmigración y su articulación concreta tanto en la elaboración de medidas jurídicas como en la realización de políticas específicas. Ese enfoque debería unir supuestamente los mecanismos de control de fronteras destinados a la lucha contra la inmigración irregular y a la repatriación de los migrantes sin papeles, por un lado, y las políticas de derechos e integración de los migrantes regularizados y las políticas de cooperación, desarrollo, paz y seguridad en los países origen de los flujos, por otro. Pero esta articulación está lejos de hacerse realidad. El Pacto Europeo sobre inmigración y asilo (2008) es uno de los ejemplos más evidentes de la enorme desproporción existente entre el primer polo y el segundo, ya que se centra fundamentalmente en las medidas de control y deja en un segundo plano todo lo demás.

Las políticas migratorias -incluso aquellas más "generosas" de la fase posbélica en Europa- siempre han sido una variable dependiente de las políticas laborales y de regulación de los mercados de trabajo y, desde la crisis del fordismo, son inseparables de las estrategias de precarización y de revocación neoliberal de las prestaciones sociales de los Estados. El giro postfordista de las políticas migratorias se ha caracterizado por una creciente criminalización de la inmigración y una subordinación de los derechos humanos a objetivos políticos no sólo de control de los flujos, sino de expulsión de los migrantes (Jansen, Celikates y de Bloois 2015). En este proceso puede reconocerse una tendencia que afecta a los países que gustan llamarse a sí mismos "democráticos" y que ha convertido en normalidad jurídica medidas de excepción legitimadas por supuestas situaciones de emergencia. En toda Europa hemos asistido a la creación de un dispositivo de dimensiones cada vez mayores que incluye campos y centros de internamiento para extranjeros, estructuras de coordinación trasnacional de órganos de represión y de procedimientos jurídicos con los que se gobierna, controla e impide la movilidad de los migrantes. Y los Estados parecen estar dispuestos a subordinar el orden jurídico o su cumplimiento efectivo a los objetivos de control, por cierto, con el apoyo de amplias capas de la población, en las que las opiniones y las actitudes xenófobas no han dejado de crecer. Lo que 
no impide en ciertos momentos implementar políticas migratorias selectivas para cubrir determinados nichos del mercado de trabajo de los países receptores.

Con todo, la propia precarización generalizada del empleo ha llevado a un cierto igualamiento que va haciendo menos atractivos a los inmigrantes como ejército de reserva para los sectores de empleo más precarizados. Lo que ha llevado a ciertas fracciones del capital y a ciertas empresas con dificultades para contratar fuerza de trabajo cualificada a proponer una apertura selectiva del acceso a inmigrantes con características específicas. Las estrategias cambian, pero la cuestión fundamental sigue siendo la misma desde los orígenes del sistema capitalista: cómo fijar la fuerza de trabajo en condiciones de rentabilidad. Y para eso sirve tanto la deslocalización empresarial como el transfer espacial de trabajadores y trabajadoras por medio de la creación de un mercado mundial de fuerza de trabajo (Cohen 1987). El régimen migratorio neoliberal ha sido, pues, un elemento clave en la transformación de los mercados de trabajo en los países ricos. De hecho, para que nuestro mercado de trabajo fuera capaz de acoger un número significativo de trabajadores del tercer mundo, primero tuvo que realizar un proceso progresivo de "tercermundización" de un sector importante de ese mercado (Pedreño 2005). Con todo, la extensión de la precariedad laboral a importantes capas de la población autóctona ha ido eliminando cada vez más las líneas de demarcación de un mercado de trabajo dual y haciendo emerger una competencia entre fuerza de trabajo autóctona e inmigrante que pone en cuestión los criterios de distribución material y simbólica de los Estados nacionales. En esta nueva coyuntura se moviliza la representación del espacio político en términos nacionales para identificar a los inmigrantes como amenaza del compromiso político social de los Estados del bienestar europeos. Compromiso que en realidad se descompone como consecuencia de la dinámica de crisis del propio sistema económico capitalista.

Casi todos los Estados desarrollados han realizado en los últimos tiempos un conjunto de reformas legislativas en política de inmigración presididas por lo que se ha llamado "lógica del regateo", estableciendo una verdadera carrera de obstáculos con amenaza permanente de recaída en la "ilegalidad", reduciendo las garantías y aumentando la discrecionalidad de la administración, promoviendo legalmente la discriminación laboral y la vulnerabilidad de los migrantes, etc. Esa forma de "gobernar" los flujos migratorios produce vulnerabilidad y sumisión laboral. El "inmigrante indocumentado" es sistemáticamente expulsado al limbo de la no existencia jurídica y política. Se ha convertido en el tipo tendencialmente ideal del trabajador en el marco del capitalismo neoliberal: siempre disponible, sin costes de seguridad social, sometido sin límites a las exigencias de la economía y sin capacidad para articular políticamente sus derechos. 
Los Estados sociales nacionales del bienestar, cuyas condiciones de posibilidad tienen que ver con una determinada distribución internacional del trabajo, la riqueza y el poder militar, parecen querer asegurar su existencia, si no con el rechazo y la exclusión de los que se considera que no forman parte del compromiso, sí como una fuerte jerarquización, selección y bloqueo del acceso a sus territorios y a sus derechos sociales. Los arquetipos racistas que se remontan a las épocas coloniales son movilizados no solo por los partidos xenófobos y de extrema derecha, sino que encuentran institucionalización jurídica, administrativa y política en el conjunto de las sociedades. El peligro hoy no es solo la nueva coyuntura del racismo, sino la extensión generalizada del chovinismo nacional como modelo de estructuración político-económico de las sociedades ricas del Norte planetario.

\section{Modo de regulación postfordista y crisis sistémica}

LA CONEXIÓN ENTRE LA CRISIS DEL RÉGIMEN migratorio neoliberal y la crisis sistémica general exige atender a las características de esta última para entender hacia dónde pueden encaminarse las políticas migratorias y cómo responder a ellas.

La crisis mundial de mitad de los años 1970 representó un momento crucial y un punto de no retorno para las condiciones de revalorización del capital en los países capitalistas desarrollados. La etapa anterior se había caracterizado por una acumulación acelerada acompañada de pleno empleo, un crecimiento de los salarios en consonancia con los crecimientos de la productividad y la construcción de Estados del bienestar basados en el pacto social de posguerra. Sin embargo, en los años siguientes, la sobreacumulación de capital, persistente a pesar de los vaivenes coyunturales, condujo a un desempleo estructural, a un desacoplamiento de la evolución de los salarios respecto a la evolución de la productividad, a la creación de nuevas formas de contratación en las franjas de bajos salarios y a un progresivo desmantelamiento o debilitamiento del Estado social. La tónica general que ha presidido esta etapa ha sido una insuficiente rentabilidad de las inversiones agregadas de capital para ampliar la producción. En lo fundamental esta tendencia sigue vigente hasta hoy, a pesar de todos los esfuerzos realizados desde entonces para contrarrestarla. Unos de los efectos reconocidos de esta sobreacumulación estructural y de la insuficiente rentabilidad de las inversiones fue el desplazamiento de los capitales no reinvertidos en el sector productivo hacia los mercados financieros, que por esa razón experimentaron un desarrollo vertiginoso. Favorecidos por la desregulación, dichos mercados produjeron sucesivas burbujas especulativas en las que los activos financieros alcanzaban una rentabilidad muy por encima de las tasas de beneficio 
de la producción industrial, sobre todo desde mitad de los años 1980. Los intereses de los inversores financieros adquirieron así un influjo creciente tanto sobre la evolución del sector productivo como sobre las políticas económicas de los Estados. La desregulación también contribuyó decisivamente a generar una presión crediticia volcada en posibilitar y forzar el consumo de las familias y el gasto de los Estados debilitados respectivamente por los recortes salariales y por la disminución de los ingresos fiscales. La crisis financiera del 2008 provocada por el hundimiento de los productos basura fruto de esta presión crediticia y representados por las subprime conduciría, por su parte, a una nueva crisis de sobreproducción.

Pero esa crisis financiera no ha caído del cielo como un meteoro extraterrestre. Con el comienzo de la crisis de sobreacumulación en la década de 1970 se volvieron hegemónicas las doctrinas económicas que solemos aglutinar bajo el término de "neoliberalismo", unas doctrinas que influyeron poderosamente en las políticas económicas y sociales de la mayoría de gobiernos. El conjunto de estrategias y medidas económicas impuestas por las políticas neoliberales tenían un objetivo fundamental: restablecer las tasas de beneficio y relanzar la acumulación de capital (con crecimiento económico). Un factor fundamental para el logro de este objetivo consistió en quebrar el compromiso de clases de posguerra y romper el equilibrio de fuerzas entre la masa de asalariados y el poder del capital en favor de este último. Debilitar a las organizaciones sociales de los asalariados que habían dado soporte a dicho compromiso y luchaban por su mantenimiento pasó a presidir la agenda política. Ese debilitamiento permitió la imposición progresiva de recortes salariales, el desmantelamiento o debilitamiento del Estado social, la eliminación de las regulaciones que ponían ciertos límites a los intereses del capital, así como la ampliación de su poder sobre el Estado y el conjunto de la sociedad (Streeck 2016).

La otra línea fundamental de política económica neoliberal para restablecer las tasas de beneficio tiene que ver con la reducción de costes de producción y distribución por medio de la reestructuración de los procesos productivos y de comercialización gracias a la incorporación de las nuevas tecnologías y de los avances en logística y transporte. A partir sobre todo de la década de 1990 hemos asistido al desarrollo de un conjunto de estrategias de deslocalización y externalización empresarial, de reorganización de la división internacional del trabajo, intensificación de la innovación tecnológica y su incorporación a la producción, de automatización y robotización, etc., así como a una transnacionalización de la explotación del trabajo a nivel global por medio de la traslación de aquellos tramos de la producción industrial y manufacturera más intensivos en mano de obra a países con salarios más bajos y, en general, de la construcción de un capitalismo en red (Castells 2006) que permite una organización flexible tanto de las inversiones y su financiación como 
de las estructuras de producción y gerencia empresarial y de las cadenas de comercialización y distribución.

Todas estas estrategias políticas y económicas neoliberales han permitido extender e intensificar la penetración capitalista de la sociedad: privatización de servicios públicos y sectores económicos estratégicos, mercantilización y configuración tecnológica de amplias áreas de la cotidianidad, del medio ambiente y, finalmente, del cuerpo y el psiquismo de los individuos a través de las redes sociales, transformación de los Estados sociales en Estados competitivos, reorganización de las relaciones de clase y de género, etc. Todas estas transformaciones dan cuenta del inmenso despliegue realizado durante cuatro décadas y revelan al mismo tiempo la profundidad de las contradicciones sistémicas a las que se enfrenta el capitalismo en su etapa actual, sobre todo si tenemos en cuenta el amenazante horizonte de "estagnación secular" pronosticado tanto por muchos de sus críticos (Roberts 2016), como por algunos de sus defensores (p.ej., Lawrence Summers, ministro de finanzas de EEUU en 2013, el Foro de Davos o el Banco Mundial, véase Kurgman 2013).

Las esperanzas de que la revolución digital podría relanzar el crecimiento económico y consolidar un nuevo régimen de acumulación estable y sólido han resultado ser vanas esperanzas. La dificultad para que las expectativas puestas en la "nueva economía" se cumplieran en un renovado impulso de acumulación intensiva proviene de que las nuevas tecnologías han establecido unos estándares de productividad y racionalización que disminuyen considerablemente la necesidad de fuerza de trabajo. Paradójicamente, el estándar de productividad digital basada en las tecnologías de la información y la comunicación ha llevado por primera vez a una insuficiente producción de valor. Las empresas punteras del capitalismo digital destruyen más empleo del que crean y solo han conseguido atraer una parte de la demanda solvente, pero no aumentarla en la medida necesaria como para relanzar el crecimiento económico (Staab 2016). En realidad, el problema sigue siendo el mismo que provocó la progresiva sustitución del aprovechamiento real del capital en la economía productiva por una economía insustancial del endeudamiento y de las burbujas financieras. No puede sorprender que el negociado más rentable de la General Motors o de Fiat sea su división financiera, ¿pero por cuánto tiempo?

Con todo, contemplando todo este proceso desde el horizonte de la crisis actual, podemos decir que el evidente fracaso de las políticas neoliberales por lo que respecta a su objetivo fundamental no ha menoscabado su hegemonía ni revertido sus efectos sociales o políticos. Tampoco la crisis que sufren las formaciones sociales capitalistas desde el 2007 ha conducido a la conformación y consolidación de movimientos sociales y políticos suficientemente potentes como para poner dicha hegemonía seriamente en peligro. Ni los movimientos altermundistas ni los escasos 
gobiernos en cuyas declaraciones programáticas decían enfrentarse a dicha hegemonía han demostrado capacidad para sustraerse a ella o debilitarla de manera sustancial. Más bien asistimos a un crecimiento del populismo autoritario que intenta capturar el descontento de las clases subalternas por medio de una división dentro del campo liberal-conservador, que no busca tanto decantar la hegemonía en el interior de ese campo, cuanto desequilibrar la balanza política general hacia la derecha. Esto permite no solo neutralizar las protestas y el descontento que se habían ido agrandando en la última fase del período neoliberal, sino además capitalizar su energía y utilizarla para reforzar el giro disciplinador de las políticas hegemónicas. Se instrumentaliza la frustración para fomentar el resentimiento frente grupos identificados por el discurso político como responsables de los problemas y dificultades propios de la crisis. El foco de atención se desvía hacia supuestas amenazas -contra la nación, contra la prosperidad duramente conquistada, contra el pueblo, etc.-, mientras que se refuerzan las estrategias de desolidarización y de estigmatización de los más desfavorecidos.

Si bien las medidas de salvamento de los bancos implementadas a partir de 2008 consiguieron impedir in extremis un colapso del sistema financiero y una segunda Gran Depresión, cuyas consecuencias hubieran sido catastróficas para el conjunto del sistema, no han conseguido resolver los problemas de fondo que están en el origen la crisis. La mayoría de los títulos basura se han depositado en los llamados "bancos malos" o en creaciones similares siguiendo una estrategia de desplazamiento temporal de la destrucción de los valores ficticios y, sobre todo, de traslación de los costes de esa destrucción a los contribuyentes vía deuda pública, lo que supone un lastre para la capacidad de inversión de los Estados y de consumo privado. A esta misma estrategia han servido las medidas de los bancos centrales con políticas de bajas tasas de interés o de sobreoferta de dinero en algunos países. El resultado de este "intervencionismo neoliberal" ha llevado a un crecimiento exorbitado de la deuda de los Estados, que las medidas para paliar el parón de la economía por la pandemia del covid-19 no hará sino aumentar. La pregunta no es ya cómo salir de la crisis sistémica, sino si habrá salida en el marco de la economía capitalista (Zamora 2017).

\section{El nuevo horizonte del desplazamiento forzado en la crisis terminal del capitalismo}

LAS DINÁMICAS ESTRUCTURALES, sus contradicciones y su propensión a las crisis, despiertan en el momento actual interrogantes de enorme calado. Aunque no se pueda afirmar con completa certeza la aparición de un límite interno infranqueable 
del proceso de acumulación capitalista, como señalan Wallerstein (2010) y Kurz (2012), cuando menos es necesario admitir que no vamos a contar con una estabilización duradera y sí probablemente con períodos más o menos largos de recesión y quizás tímidas recuperaciones. La tercera revolución industrial no permite generar los círculos económicos "virtuosos" del fordismo. Mantener las tasas de beneficio cada vez permite menos la financiación de la reproducción de la vida de los que el sistema económico declara "superfluos". El imperialismo expansivo que incorporaba territorios y poblaciones al proceso de revalorización capitalista ha dejado paso a un imperialismo de exclusión para el que una masa creciente de individuos y territorios se convierten en inservibles para esa revalorización. Las formas de "reconocimiento" de los sujetos nacionales de derecho que acompanó como un modelo de lujo a la expansión capitalista postbélica en los centros del sistema capitalista, se van descomponiendo progresivamente en la misma medida que el endeudamiento público que las ha sostenido en las últimas cuatro décadas se vuelve inviable a largo plazo. El sostenimiento de la acumulación exige hoy formas de expropiación y saqueo que desencadenan movimiento de huida y desplazamientos masivos, pero el injustificable rechazo y el blindaje de las fronteras posee una razón objetiva en la misma crisis civilizatoria que pone de manifiesto la creciente imposibilidad de universalizar un bienestar mediado por la revalorización del capital.

La ilusión que se manifestaba en los momentos álgidos del fordismo bajo la ideología de la "ayuda al desarrollo" de que era posible una universalización de los estándares de bienestar de los centros de sistema capitalista ha dejado paso a un desentendimiento y un abandono de las zonas devastadas por una mezcla de violencia económica, bélico-militar y ecocida. Esas masas de desplazados son percibidas como amenaza y rechazadas. El régimen actual de acumulación sólo da para unos pocos. La media verdad que se esconde tras la afirmación de que "no es solución que todos vengan aqui", silencia la otra mitad: "tampoco que se queden allî", a no ser que esto implique asumir su extinción.

Eso es lo que realmente expresan los eslóganes xenófobos que encuentran cada vez más eco en las opiniones públicas europeas: "La France pour les Français!", "Deutschland zuerst!" o "American first". Cada vez cobra mayor aceptación una defensa abierta de la desigualdad, que puede estar fundada en la pertenencia o no a una determinada nación, pero también puede basarse en marcadores sociales de propiedad, empleo, consumo, etc. El efecto más inmediato es la recodificación nacional de los derechos sociales o su condicionamiento disciplinador, así como el establecimiento de prioridades de acceso y el desmantelamiento de los mecanismos de equiparación jurídica de las personas que habitan en un territorio, algo en marcha desde hace décadas. Se legitime con argumentos supremacistas o no, en 
todo caso crece entre los ciudadanos europeos la aceptación de diferentes tipos de prelación en el acceso a recursos y a derechos, ya sea de corte étnico-nacional o de tipo social (los que contribuyen al bienestar nacional con su esfuerzo y los que son una carga por su incapacidad para contribuir a él, por ejemplo).

Si bien el racismo biologicista ha perdido vigencia, no ocurre lo mismo con el racismo de la diferencia o diferencialista. Este permite, igualmente, legitimar políticas de segregación o de estratificación política o, incluso, de control fronterizo duro, discriminatorio y, dado el caso, violento. La concepción de fondo que da respaldo a este elemento desigualitario del populismo autoritario es el darvinismo social que promueve no solo la competencia individualista como mecanismo de regulación de las relaciones sociales, sino también la prevalencia de los más fuertes o exitosos. Bajo una lógica de evolución natural, la atención a los débiles o a los vulnerabilizados debilita al conjunto. Por eso el humanitarismo se convierte en blanco de la crítica y es presentado como una amenaza para la integridad nacional. El derecho de no devolución que asiste a los demandantes de asilo queda suspendido por un supuesto derecho de las naciones a la no aceptación de sus demandas en razón de una soberanía nacional tan desmedida como irreal, pero que convierte en papel mojado la Convención de Ginebra para los propios Estados signatarios.

La multiplicación de los muros entre la riqueza y la pobreza son una manifestación de la violencia que va a ser precisa para mantener a raya a la "humanidad sobrante". Esta proliferación y transformación de las barreras/fronteras (administrativas, sanitarias, de protección social, etc.) indica además una evolución en el sentido de que también a una parte creciente de los antiguos sujetos nacionales de derecho se va a ver afectada por el destino de la "humanidad sobrante". La ciudadanía estado-nacional capitalista no se encuentra en expansión, sino en contracción. Es posible que, a medio plazo, la cotidianeidad en Europa termine por adquirir esta forma de "geografía elástica" con campos de internamiento, guetos, zonas especiales o de acceso limitado, etc.

Las políticas migratorias europeas y las zonas de muerte que han creado en sus fronteras muestra con toda claridad que los grandes principios de la modernidad política como ciudadanía, derechos humanos, democracia y humanismo no pueden universalizarse en una sociedad capitalista, pues sus formas de configurar lo social producen un vuelco entre medios y fines por la que la reproducción de la vida depende del proceso de revalorización del capital. Esto es lo que Marx y la Teoría Crítica llaman "sociedad invertida". Medios y fines invierten el rango. Y esto tiene consecuencias para hacer valer el máximo principio de la modernidad: la afirmación kantiana de que el ser humano es un fin en sí mismo. Mientras que la revalorización del capital generaba excedentes que permitían amortiguar en los paí- 
ses ricos las consecuencias sociales de la injusticia sistémica, la fuerza destructora de esa inversión instrumental podía ser limitada o pasada por alto. En el momento en el que el capitalismo parece chocar con límites a su proceso aparentemente infinito de revalorización, los "fines en sî" se ven amenazados. El sostenimiento de la vida entra en contradicción abierta con las leyes de la acumulación y el espacio de la solidaridad y de los derechos humanos se reduce. La apariencia de una vía política propia en Europa que debía mostrar al mundo que es posible un capitalismo con rostro humano, tanto hacia adentro como hacia afuera, desaparece después de décadas de políticas neoliberales y como consecuencia de la actual crisis. Los más débiles entre los ciudadanos nacionales europeos lo experimentan de manera cada vez más despiadada. Pero esa contradicción alcanza una inusitada dureza frente a los migrantes que se juegan la vida para poder salvarla de alguna manera. Cuando la vida queda reducida a mera lucha por la supervivencia, porque la supervivencia misma fue convertida en medio de la revalorización del capital, entonces el "sí mismo" deja de ser un "fin en sî". La otra cara de una autoconservación que sacrifica a su sujeto es la pérdida de valor de todos aquellos cuya vida es reducida a la mera supervivencia. 


\section{Referencias Bibliográficas}

Alonso, Luis E. 1999. Trabajo y ciudadanía. Madrid: Trotta.

Balibar, Étienne. 1998. “The Borders of Europe”. En P. Cheah \& B. Robbins (ed.) Cosmopolitics: Thinking and Feeling beyond the Nation, Minneapolis: University of Minnesota Press, 216-229.

Balibar, Étienne. 2003. Nosotros, ¿ciudadanos de Europa? Las fronteras, el Estado, el pueblo. Madrid: Tecnos.

Bedszant, Gerd. 2014. Zusammenbruch der Peripherie. Berlín: Horlemann.

Buckel, Sonja. 2015. "The Rights of the Irregularized". En R. Celikates, J. de Boois, and Y. Jansen (eds.). The Irregularization of Migration in Europe. Londres: Rowman \& Littlefield, 137-152.

Castells, Manuel. 2006. La Sociedad Red. Madrid: Alianza.

Chick, Kristen. 2015. "Seeking Refuge: Greece, long hostile to migrants, turns hospitable under Syriza”. Christian Science Monitor, 24-6-2015. Recuperado de http://www.csmonitor.com/World/Europe/2015/0624/Seeking-Refuge-Greece-long-hostile-to-migrants-turns-hospitable-under-Syriza.

Cohen, Robin. 1987. The New Helots. Aldershot: Avebury.

Crossa Niell, Mateo. 2017. Cadenas globales de valor. Cuadernos de Economía Critica 3 (6): 71-100.

Damir-Geilsdorf, Sabine (ed.). 2016. Bonded Labour Global and Comparative Perspectives. Bielefeld: Transript.

De Genova, Nicholas y Nathalie Peutz. 2010. Deportation Regime. Durham: Duke U.P.

Demirovic, Alex et al. (eds.). 2011. Vielfachkrise im finanzmarktdominierten Kapitalismus. Hamburg: VSA.

Díaz-Salazar, Rafael. 2003. Trabajadores precarios. Madrid: HOAC.

Domínguez, Mario y J. L. Moreno. 1997. “Exclusión”. Politica y Sociedad 25: 229-243.

FitzGerald, David Scott. 2019. Refuge beyond Reach. How Rich Democracies Repel Asylum Seekers. Nueva York: Oxford U.P.

Gerstenberger, Heide. 2017. Markt und Gewalt. Münster: West. Dampfboot. 
González Cámara, Noelia. 2011. Migrantes, procesos de irregularización y lógicas de acumulación y exclusión. Tesis doctoral. Recuperado de http://digital.csic.es/ bitstream/10261/49049/1/TD\%20-\%20Noelia\%20Gonzalez.pdf. Accessed 6 Dec 2016.

Harvey, David. 2003. The New Imperialism. Nueva York: Oxford U.P.

Hess, Sabine y Bernd Kasparek (eds.). 2010. Grenzregime. Berlín: Assoziation A.

Huiyao, Wang. 2015. Annual Report on Chinese International Migration. Recuperado de http://en.ccg.org.cn/annual-report-on-chinese-international-migration2015/

Jansen, Yolande, Robin Celikates y Joost de Bloois (eds.). 2015. The Irregularization of Migration in Contemporary Europe. Londres: Rowman \& Littlefield.

Karakayali, Serhat. 2015. "Illegal Migration in Post-Fordism”. En R. Celikates, J. de Boois, and Y. Jansen (eds.). The Irregularization of Migration in Europe. Londres: Rowman \& Littlefield, 31-52.

Kliman, Andrew. 2012. The Failure of Capitalist Production. Londres: Pluto Press.

Krugman, Paul. 2013. Secular Stagnation, Coalmines, Bubbles, and Larry Summers. New York Times, 16. Noviembre. Recuperado de https://krugman. blogs.nytimes.com/2013/11/16/secular-stagnation-coalmines-bubbles-and-larry-summers/?_r=3.

Kurz, Robert. 2012. Geld ohne Wert. Berlín: Horlemann.

Mateo, Juan Pablo (ed.). 2015. Capitalismo en recesión. Madrid: Maia.

Mezzadra, Sandro. 2005. Derecho de fuga. Madrid: Traficantes de Sueños.

Mezzadra, Sandro. 2013. "Capitalismo, migraciones y luchas sociales”. En Alejandra Aquino et al. (eds.). Desafiando fronteras. Oaxaca: sur+ ediciones, 41-54.

Mezzadra, Sandro y Brett Nielson. 2014, "Fronteras de inclusión diferencial", Papeles del CEIC, vol. 2, no 113. http://dx.doi.org/10.1387/pceic.12980.

Mezzadra, Sandro y Brett Neilson. 2017. La frontera como método. Madrid: Traficantes de sueños.

Moore, Jason W. 2003. Nature and the Transition from Feudalism to Capitalism. Review: A Journal of the Fernand Braudel Center 26 (2): 97-172.

Moore, Jason W. 2013a. El auge de la ecología-mundo capitalista, I. Laberinto 38: 9-26. 
Moore, Jason W. 2013b. El auge de la ecología-mundo capitalista, II. Laberinto 39: 21-29.

Moore, Jason W. 2014. "The End of Cheap Nature”. En C. Suter and C. Chase-Dunn (eds.). Structures of the World Political Economy and the Future of Global Conflict and Cooperation. Berlín: LIT, 285-314.

Pedreño, Andrés. 2005. “Sociedades etnofragmentadas”. En A. Pedreño y M. Hernández (eds.). La condición emigrante. Murcia: Universidad de Murcia, 75103.

Ribas Mateos, Natalia (ed.). 2011. El Río Bravo Mediterráneo. Barcelona: Bellaterra.

Roberts, Michael. 2016. La Larga Depresión. Madrid: El Viejo Topo.

Rodríguez Rodríguez, Rosa María. 2013. Ciudadanía, inmigración y exclusión social. Madrid: Publicaciones Congreso de Diputados.

Silveira Gorski, Héctor C. 2008. "El asilo y el declive del Estado de derecho en la frontera sur”. En AAVV, Frontera Sur, Barcelona: Virus, 181-193.

Simmel, G. 1908. Soziologie. Untersuchungen über die Formen der Vergesellschaftung. Gesamatausgabe 11. Frankfurt/M.: Suhrkamp, 1992.

Staab, Philipp. 2016. Falsche Versprechen. Wachstum im digitalen Kapitalismus. Hamburg: Hamburger Edition HIS.

Streeck, W. 2016. Comprando tiempo La crisis pospuesta del capitalismo democrático. Madrid: Katz.

Transit Migration Forschungsgruppe. 2007. Turbulente Ränder. Bielefed: transcript.

Velasco, Juan Carlos. 2016a. El azar de las fronteras. México: FCE.

Wallerstein, Immanuel. 1984. The Politics of the Worl-Economy. Cambridge: Cambridge U.P.

Wallerstein, Immanuel. 2010. "Structural Crisis". New Left Review 62: 133-142.

Zamora, José A. 2017. "Crisis del capitalismo: callejones sin salida y transiciones postcapitalistas”, Iglesia Viva 272: 11-40.

DOI: http://dx.doi.org/10.15366/bp.2020.23.002

Bajo Palabra. II Época. No23. Pgs: 49-72 